GRASAS Y ACEITES 70 (1)

January-March 2019, e290

ISSN-L: 0017-3495

https://doi.org/10.3989/gya.0579181

\title{
Mid-infrared spectroscopic detection of sunflower oil adulteration with safflower oil
}

\author{
O. Uncu, B. Ozen ${ }^{凶}$ and F. Tokatli \\ Izmir Institute of Technology, Department of Food Engineering, Urla-Izmir \\ ${ }^{\square}$ Corresponding author: banuozen@iyte.edu.tr
}

Submitted: 24 May 2018; Accepted: 03 September 2018

SUMMARY: The oil industry is in need of rapid analysis techniques to differentiate mixtures of safflower-sunflower oils from pure oils. The current adulteration detection methods are generally cumbersome and detection limits are questionable. The aim of this study was to test the capability of a mid-infrared spectroscopic method to detect the adulteration of sunflower oil with safflower oil compared to fatty acid analysis. Mid-infrared spectra of pure oils and their mixtures at the $10-60 \%$ range were obtained at $4000-650 \mathrm{~cm}^{-1}$ wavenumber and fatty acid profiles were determined. Data were analyzed by multivariate statistical analysis techniques. The lowest level of detection was obtained with mid-infrared spectroscopy at $30 \%$ while the fatty acid profile could determine adulteration at around $60 \%$. Adulteration levels were predicted successfully using PLS regression analysis of infrared data with $\mathrm{R}^{2}$ (calibration) $=0.96$ and $\mathrm{R}^{2}$ (validation) $=0.93$. As a rapid and minimum waste generating technique, mid-infrared spectroscopy could be a useful tool for the screening of raw material to detect safflower-sunflower oil mixtures.

KEYWORDS: Adulteration; Chemometrics; Mid-infrared spectroscopy; Safflower oil; Sunflower oil

RESUMEN: Detección de la adulteración del aceite de girasol con aceite de cártamo mediante espectroscópica de infrarrojo medio. La industria aceitera necesita técnicas de análisis rápidas para diferenciar las mezclas de aceites de cártamo y girasol de los aceites puros. Los métodos actuales de detección de adulteración son generalmente engorrosos y los límites de detección son cuestionables. El objetivo de este estudio es probar la capacidad de un método espectroscópico de infrarrojo medio para detectar la adulteración del aceite de girasol con aceite de cártamo en comparación con el análisis de ácidos grasos. Se obtuvieron espectros de infrarrojo medio de aceites puros y sus mezclas en un rango de $10-60 \%$ a $4000-650 \mathrm{~cm}^{-1}$ de longitud de onda y se determinaron los perfiles de ácidos grasos. Los datos se analizaron mediante técnicas de análisis estadístico multivariante. El nivel más bajo de detección se obtuvo con espectroscopia de infrarrojo medio al 30\%, mientras que el perfil de ácidos grasos podría determinar la adulteración en torno al 60\%. Los niveles de adulteración se predijeron con éxito mediante el análisis de regresión PLS de datos infrarrojos con $\mathrm{R}^{2}$ (calibración) $=0,96$ y $\mathrm{R}^{2}$ (validación) $=$ 0,93 . Como una técnica rápida y de generación residuos mínimos, la espectroscopia de infrarrojo medio podría ser una herramienta útil para el cribado de materia prima para detectar mezclas de aceite de cártamo y girasol.

PALABRAS CLAVE: Aceite de cártamo; Aceite de girasol; Adulteración; Espectroscopía de infrarrojo medio; Quimiometría

ORCID ID: Uncu O https://orcid.org/0000-0001-7710-624X, Ozen B https://orcid.org/0000-0002-0428-320X, Tokatli F https://orcid.org/0000-0003-2643-5523

Citation/Cómo citar este artículo: Uncu O, Ozen B, Tokatli F. 2019. Mid-infrared spectroscopic detection of sunflower oil adulteration with safflower oil. Grasas Aceites 70 (1), e290. https://doi.org/10.3989/gya.0579181

Copyright: (C2019 CSIC. This is an open-access article distributed under the terms of the Creative Commons Attribution 4.0 International (CC BY 4.0) License. 


\section{INTRODUCTION}

Adulteration is a major problem for the food industry with significant economical and health consequences as in the case of toxic oil syndrome (Lai et al., 1994). There are various studies in the literature regarding adulteration detection techniques which focus on fats and oils (Jha et al., 2016; GómezCaravaca et al., 2016; Tena et al., 2015; Ellis et al., 2012). Creative fraud techniques necessitate the development of new adulteration detection methods or the update of existing ones. In general, most official methods that aim to detect adulteration are based on chromatographic detection of compounds such as sterols and include extensive time requirements and laborious extraction steps.

Safflower oil is mixed with sunflower oil in high proportions since this oil is relatively cheaper. Even small differences between oil prices result in high profits when large amounts of oils are mixed. The oil industry have complaints (personal communication) about the difficulty in detecting the adulteration of sunflower oil with safflower oil even with traditional chemical analysis techniques due to the resemblance in chemical composition (fatty acid, sterol etc.) between safflower oil and sunflower oil (Hurriyet, 2016).

Adulteration detection methods could be classified under two groups: targeted and non-targeted analytical methods (Aparicio et al., 2013). While targeted techniques are based on the identification of specific compounds such as fatty acids, sterols or tocopherols in the sample, a non-targeted approach provides a general view of the molecular structure of the analyzed compounds. It is well-documented in the literature that infrared (IR) spectroscopic methods as non-targeted analytic techniques are quite successful in detecting the adulteration of various oils even at low adulteration levels (Azizian et al., 2015; Mendes et al., 2015; Gurdeniz and Ozen, 2009). In addition, these methods have the advantages of being rapid and relatively more environmentally friendly since they require minimum sample preparation. Qualitative and quantitative applications of mid-IR spectroscopy in the $4000-400 \mathrm{~cm}^{-1}$ range of electromagnetic spectrum is a common practice in the analysis of organic compounds in order to identify the specific chemical structures of a matrix (Guillén and Cabo, 1997). This measurement technique is based on the fact that bonds of certain atomic groups have specific modes of vibration (stretching and/ or bending) under mid-IR absorption which lead to a qualitative representation of molecular structure at characteristic frequencies (Karoui et al., 2008). One reason for the success of these spectroscopic methods is the use of chemometric techniques in the analysis of the data since the complex data obtained from spectroscopic measurements could be converted into a meaningful form with the application of these statistical methods.

Near and mid-IR spectroscopic techniques are reported in the literature to have been commonly used in authentication studies related mostly with olive oil. As a mid-IR spectroscopic technique Fourier transform infrared (FTIR) spectroscopy in combination with chemometric tools was able to detect a corn-sunflower-canola mixture in olive oil at the 5\% level (Gurdeniz and Ozen, 2009). In another study that used various multivariate statistical data analysis approaches, oils that came from different botanical origin (olive, sunflower, corn, soybean and hazelnut) were differentiated from each other and percentages of binary mixtures in olive oil were predicted with FTIR spectroscopy (Lerma-García et al., 2010). There are also examples of the use of FTIR spectroscopy in the adulteration detection of various oils other than olive oil. This spectroscopic technique and chemometric data analysis were also successful in detecting the mixtures of animal fat in cod-liver oil (Rohman and Che Man, 2009). Both mid and near IR spectroscopy were used in identifying soybean oil added to camellia oil and it was reported that both methods were effective in the detection and quantification of adulteration (Wang et al., 2006). However, there is no report in literature about the detection of safflower in sunflower oil with any analytical methods. This study was aimed to use FTIR spectroscopy and various chemometric tools to detect the adulteration of sunflower oil with safflower oil in comparison to the fatty acid profile analysis. This study was undertaken upon request from the sunflower oil industry.

\section{MATERIALS AND METHODS}

\subsection{Samples}

Nine crude sunflower oils and 6 crude safflower oils were supplied by an oil company. Adulterated samples were prepared by adding safflower oils to each of the sunflower oil samples at 10, 30, 50 and $60 \%(\mathrm{v} / \mathrm{v})$ and 216 adulterated samples (9 sunflower oils $\mathrm{x} 6$ safflower oils $\times 4$ concentrations $=$ 216 mixtures) in total were analyzed as well as pure sunflower and safflower oils $(9+6=15)$.

\subsection{Fatty acid profile}

The fatty acid profiles of the oil samples were determined according to European Official Methods of Analysis (European Union Commission, 1991). After methylation with a cold solution of $\mathrm{KOH}$ in methanol, the extracted samples were analyzed with a GC (Agilent 6890, Agilent Technologies, USA) equipped with an auto-sampler (Agilent 7863 \& FID) and a split/splitless (1:50) injector. A HP 88 capillary column (Agilent, USA) with 
dimensions of $100 \mathrm{~m} \times 0.25 \mathrm{~mm}$ ID $\times 0.2 \mu \mathrm{m}$ was used in the GC analyses.

\subsection{FTIR spectroscopy}

Spectra of the oil samples were collected against air background in mid-IR region $\left(4000-650 \mathrm{~cm}^{-1}\right)$ with a FTIR spectrometer (Spectrum 100, Perkin Elmer, USA) equipped with a ZnSe-horizontal attenuated total reflectance (HATR) accessory and a DTGS detector. Resolution was set to $4 \mathrm{~cm}^{-1}$ and 64 scans were taken for each sample. The ZnSe crystal was cleaned with hexane, ethanol and distilled water after each run.

\subsection{Data analysis}

Orthogonal partial least square-discriminant analysis (OPLS-DA) and soft independent modeling class analogy (SIMCA) as supervised chemometric tools were used in the differentiation of pure oils from adulterated sunflower oil samples with respect to their fatty acid profiles and mid-IR spectra. The number of components in OPLS-DA is given as $\left(\mathrm{p}_{\mathrm{p}}, \mathrm{p}_{\mathrm{o}}\right)$. The $\mathrm{p}_{\mathrm{p}}$ and $\mathrm{p}_{\mathrm{o}}$ are the number of components which explain the information in the $\mathrm{X}$ matrix predictive to the $\mathrm{Y}$ matrix, and information of the $\mathrm{X}$ orthogonal to $\mathrm{Y}$, respectively.

A prediction of adulteration percentages was performed with partial least square (PLS) regression.
The classification and prediction ability of the models was checked with coefficients of determination, $\mathrm{R}^{2}$ (calibration) and $\mathrm{R}^{2}$ (cross validation), and variable importance for the projection (VIP) and root mean square error of estimation (RMSEE), cross validation (RMSEcv), and prediction (RMSEP). The leave-one-out cross-validation technique was used to check the validation performance of the model. Data were analyzed with Simca 13.0.3 (Umetrics Co., Umea, Sweden) software. The Software determines the number of necessary principal components (PC) to build the models with respect to $\mathrm{R}^{2}$ validation values.

\section{RESULTS AND DISCUSSION}

\subsection{Differentiation with respect to fatty acid profile}

The fatty acid profiles of crude sunflower and safflower oils are shown in Table 1. The major fatty acids for both seed oils were found as palmitic, stearic, oleic and linoleic acids in varying amounts. The palmitic acid content of safflower oil lies between $6.72 \%$ and $6.94 \%$ while it is between $6.22 \%$ and $7.46 \%$ in sunflower oil. In addition, the amount of stearic acid in safflower oil ranges between 2.47 and $3.09 \%$ and that of sunflower is between 2.94 and $3.86 \%$. Therefore, both palmitic and stearic acid contents of sunflower and safflower oils generally overlap with each other. However, the oleic and linoleic acid contents in

TABLE 1. Fatty acid profiles of pure safflower and sunflower oil (\%).

\begin{tabular}{|c|c|c|c|c|c|c|c|c|c|c|c|c|c|}
\hline Sample & $\begin{array}{c}\text { Sample } \\
\text { code** }\end{array}$ & C14:0 ${ }^{1}$ & C16:0 $0^{2}$ & C16:1 ${ }^{3}$ & C18:0 $0^{4}$ & $C 18: \ln 9 \mathrm{c}^{5}$ & $C 18: 2 n 6 c^{6}$ & C18:3n $3^{7}$ & C20:0 ${ }^{8}$ & C20:1 ${ }^{9}$ & C22: $0^{10}$ & C24:0 $0^{11}$ & $\mathrm{C} 24: 1^{12}$ \\
\hline \multirow{6}{*}{$\begin{array}{l}\text { Safflower } \\
\text { oil }\end{array}$} & SA1 & 0.11 & 6.77 & 0.08 & 2.78 & 11.94 & 77.12 & 0.16 & 0.38 & 0.10 & 0.23 & 0.09 & 0.18 \\
\hline & SA2 & 0.11 & 6.92 & 0.08 & 2.49 & 12.29 & 76.86 & 0.16 & 0.36 & 0.10 & 0.23 & 0.11 & 0.25 \\
\hline & SA3 & 0.11 & 6.94 & 0.09 & 2.47 & 16.37 & 72.75 & 0.18 & 0.35 & 0.11 & 0.24 & 0.13 & 0.20 \\
\hline & SA4 & 0.12 & 6.87 & 0.08 & 2.78 & 11.87 & 77.01 & 0.17 & 0.39 & 0.09 & 0.23 & 0.11 & 0.23 \\
\hline & SA5 & 0.11 & 6.72 & 0.08 & 3.09 & 12.02 & 76.68 & 0.17 & 0.40 & 0.09 & 0.23 & 0.12 & 0.26 \\
\hline & SA6 & 0.12 & 6.85 & 0.08 & 2.74 & 13.26 & 75.67 & 0.17 & 0.38 & 0.11 & 0.22 & 0.13 & 0.21 \\
\hline \multirow{9}{*}{$\begin{array}{l}\text { Sunflower } \\
\text { oil }\end{array}$} & SU1 & 0.10 & 6.68 & 0.16 & 3.12 & 35.76 & 53.38 & ND & 0.30 & ND & 0.50 & ND & ND \\
\hline & SU2 & 0.09 & 7.03 & 0.11 & 3.86 & 23.25 & 64.33 & 0.14 & 0.25 & 0.13 & 0.63 & 0.19 & ND \\
\hline & SU3 & 0.10 & 7.46 & 0.17 & 3.25 & 29.19 & 58.48 & 0.10 & 0.22 & 0.06 & 0.61 & 0.21 & 0.16 \\
\hline & SU4 & 0.08 & 7.26 & 0.12 & 3.74 & 23.50 & 64.08 & 0.10 & 0.23 & 0.24 & 0.48 & 0.16 & ND \\
\hline & SU5 & 0.08 & 6.40 & 0.13 & 3.40 & 30.36 & 57.89 & 0.20 & 0.25 & 0.21 & 0.57 & 0.16 & 0.35 \\
\hline & SU6 & 0.08 & 7.04 & 0.13 & 3.03 & 29.67 & 58.71 & 0.13 & 0.22 & 0.12 & 0.61 & 0.26 & ND \\
\hline & SU7 & 0.10 & 6.93 & 0.14 & 3.41 & 28.38 & 59.59 & 0.12 & 0.24 & 0.14 & 0.61 & 0.22 & 0.13 \\
\hline & SU8 & 0.08 & 6.22 & 0.16 & 3.22 & 36.41 & 52.28 & 0.16 & 0.25 & ND & 0.72 & 0.28 & 0.10 \\
\hline & SU9 & 0.08 & 6.48 & 0.14 & 2.94 & 33.59 & 55.19 & 0.16 & 0.20 & 0.06 & 0.70 & 0.26 & 0.14 \\
\hline
\end{tabular}

ND means non detectable and defined as $\leq 0.05 \%$,

Differences among samples were determined by multivariate analyses (OPLS-DA) only

Standard deviations of each fatty acid were calculated from three repeated measurements: ${ }^{1}$ myristic acid: $\pm 0.00,{ }^{2}$ palmitic acid: \pm 0.01 , ${ }^{3}$ palmitoleic acid: $\pm 0.00,{ }^{4}$ stearic acid: $\pm 0.00,{ }^{5}$ oleic acid: $\pm 0.02,{ }^{6}$ linoleic acid: $\pm 0.07,{ }^{7}$ linolenic acid: $\pm 0.00,{ }^{8}$ arachidic acid: $\pm 0.00,{ }^{9}$ gondoic acid: $\pm 0.01,{ }^{10}$ behenic acid: $\pm 0.00,{ }^{11}$ lignoceric acid: $\pm 0.01,{ }^{12}$ nervonic acid: \pm 0.02 .

$* 6$ different safflower oil and 9 different sunflower oil samples were analyzed 
safflower and sunflower oils are quite different from each other. While oleic acid composes $11.87-16.37 \%$ of the tested safflower oil samples, the sunflower oil samples contain 23.25 to $36.41 \%$ oleic acid. The linoleic acid contents in safflower and sunflower oils range between $72.75-77.12 \%$ and $52.28-64.33 \%$, respectively. The rest of the fatty acids were found in similar amounts for sunflower and safflower oil samples. According to the literature, safflower oil has a variable fatty acid profile and the palmitic, stearic, oleic and linoleic acid contents of most commonly known safflower oils range between 6-8\%, 2-3\%, $16-20 \%$ and $71-75 \%$, respectively (Knowles, 1989; Velasco and Fernández-Martínez, 2001). However, these ranges may differ depending on variety (genotype), growing conditions and cultivation locations of the plant (Yeilaghi et al., 2012; Cosge et al., 2007; Gecgel et al., 2007; Fernández-Martínez et al., 1993). The safflower oil used in this study, in general, covers these ranges in the literature; therefore, provide sufficient variation required for adulteration studies. The sunflower oil samples also have a wide fatty acid composition range.

Since it is a waste of resources and time to determine the fatty acid profiles of all mixtures (216 samples) using GC measurement, the fatty acid content of each mixture was calculated using the composition of pure oils by taking into account mixture percentages. However, the fatty acid profiles of 8 mixtures were also measured experimentally and calculated vs the measured amounts were correlated with each other. As a result, it was determined that the $R^{2}$ values for the relation between calculated and measured amounts of fatty acids for all 8 mixtures were higher than 0.99. Therefore, the calculated fatty acid profiles of all the mixtures were used in the multivariate statistical analysis to observe the differentiation power of the fatty acid profile in order to detect adulteration of sunflower oil with safflower oil.

Differentiation among oil samples was investigated using multivariate discriminant analysis techniques such as PLS-DA, OPLS-DA and SIMCA and OPLS-DA provided better discrimination among oil samples compared to PLS-DA; therefore, the results of only OPLS-DA are discussed. First, OPLS-DA was run only for pure oils and pure safflower and sunflower oils are separated from each other very well $\left(\mathrm{R}^{2}\right.$ (calibration) $=0.67$ and $\mathrm{R}^{2}$ (cross-validation) $=0.95$ ) with respect to the first principal component (PC1) (graph not shown). The Loading plot (graph not shown) indicated that the higher contents of palmitoleic (16:1), stearic (18:0), oleic $(18: 1)$ and behenic (22:0) acids for sunflower oil and higher amounts of myristic (14:0), linolenic (18:2n6), and arachidic (20:0) acids of safflower oil were the fatty acids causing differentiation between these oils. VIP values of the model (not shown), which indicate the importance of each variable in the model, also proved that the mentioned fatty acids had higher discriminatory power than the rest of the fatty acids. Therefore, ineffective fatty acids are removed from the data set for further evaluations.

As far as the differentiation of mixtures is concerned, with respect to their fatty acid contents, both OPLS-DA and SIMCA were used in the data analysis. The OPLS-DA model of the fatty acid data has $\mathrm{R}^{2}$ (calibration) and $\mathrm{R}^{2}$ (cross-validation) of 0.83 and 0.16 , respectively. A OPLS-DA model was built with $(1+1)$ PC. Figure 1 shows the OPLS-DA score plot (Figure 1a) and loading plot (Figure 2b) of pure sunflower, safflower and mixture oils. The first PC in the score plot explains $62 \%$ of variability while the second PC corresponds to $21 \%$ of variability. From the score plot, it could be seen that only pure sunflower and safflower and also higher levels of adulterated samples (50\% (v/v) and 60\% (v/v)) were separated from each other while lower levels of adulterated samples $(10 \%$ and $30 \%)$ were not clustered or differentiated clearly. The loading plot (Figure $1 \mathrm{~b}$ ) revealed that the fatty acids used in the model were effective only in the differentiation of pure sunflower and samples with high safflower oil percentages. The misclassification analysis for the constructed OPLS-DA model is given in Table 2. According to this table, 30 and 13 out of 54 samples at 10 and $30 \%$ adulteration levels, respectively, were misclassified as pure sunflower oil. Although there were misclassifications above the $30 \%$ level none of the misclassified samples was assigned to the pure sunflower oil group. As an example, 1 of the samples from the $50 \%$ adulteration level was assigned to the $30 \%$ level while 5 of them were grouped as $60 \%$ mixture. Therefore, it could be concluded that adulteration detection using fatty acid profile is possible at around $50 \%$ mixture level according to the misclassification table.

In addition, SIMCA models (Figure 2) were also created to see the differentiation power of fatty acids in the detection of adulteration with safflower oil. As seen in Figure 2a, all samples of 10\% safflowersunflower mixtures and even most of the pure sunflower samples are located in the common region of Cooman's plot. This indicates that detection at this level is not possible. At the 30\% level a clear separation is still not possible because most of the adulterated samples are in the common region (Figure 2b). There is a clearer differentiation between pure and mixed samples at the $50 \%$ level but some of the samples are still in the common region of the plot (Figure $2 \mathrm{c}$ ), while at the $60 \%$ level of adulteration there is a clear separation between pure and adulterated samples (Figure 2d). Therefore, the 60\% adulteration level is the critical percentage in the detection of adulteration of sunflower oil with safflower oil using fatty acid profile. OPLS-DA discrimination resulted in lower detection limit of 50\% compared to SIMCA but this is still a high value. In other words, 

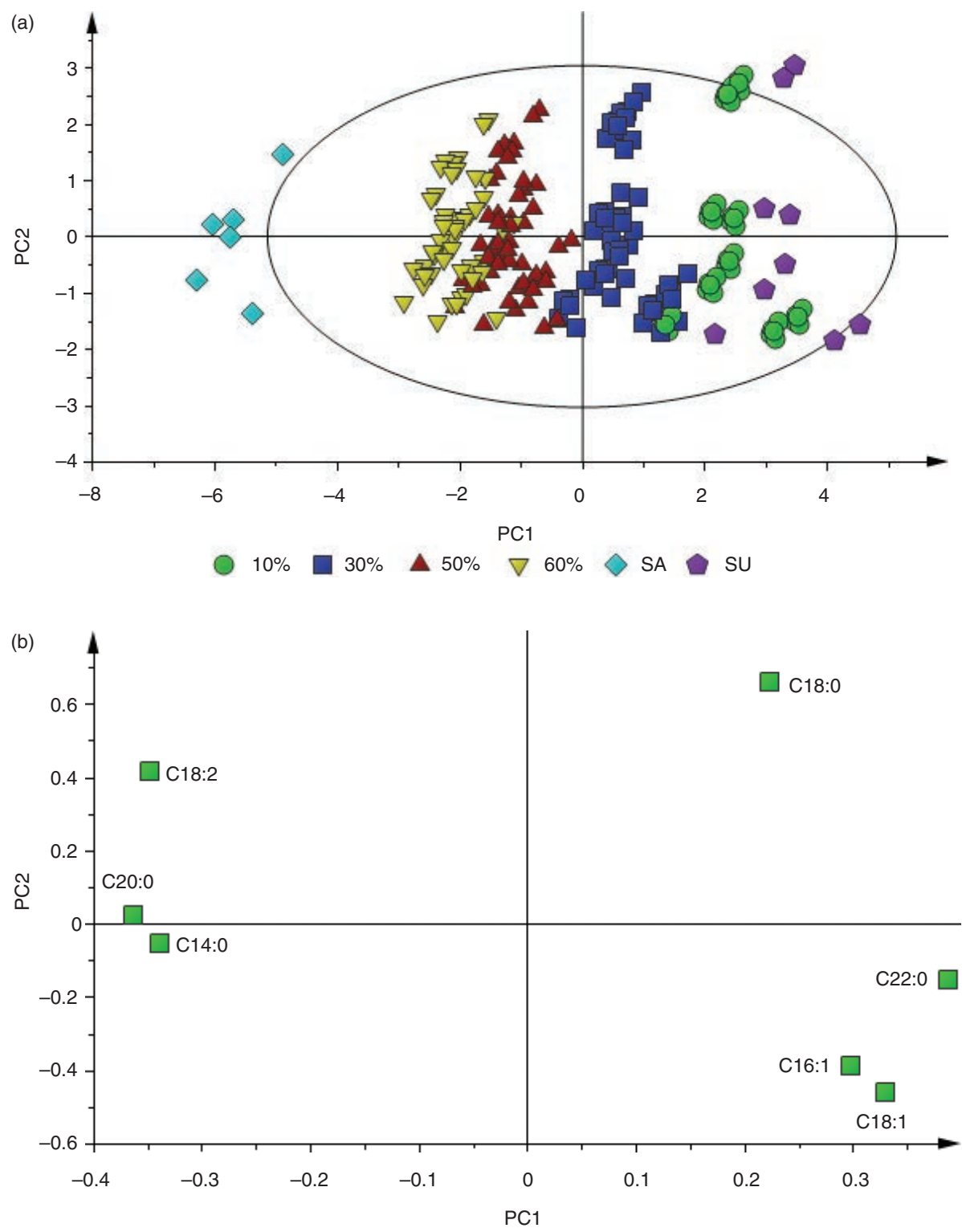

FIGURE 1. (a) Score and (b) Loading plots of an OPLS-DA model constructed with fatty acid profiles of pure sunflower (SU) and safflower (SA) oil samples and mixtures of safflower oil in sunflower oil at varying levels.

fatty acid profile is not very satisfactory for the differentiation of adulterated sunflower oil. It was reported that while fatty acid profile could detect adulteration of olive oil with various oils (soybean, corn, and sunflower) at levels as low as $2 \%$ (Jabeur et al., 2014), it was not effective in determining mixtures of hazelnut oil-olive oil or almond oil-olive oil (Christopoulou et al., 2004).

\subsection{Mid-infrared spectroscopic detection of adulteration}

Mid-IR spectra of pure sunflower and safflower oils and their mixtures were also collected to be used as an authentication tool and the spectra indicate no clear visible differences among samples (Figure 3). However, multivariate statistical analysis of the data is generally very effective in revealing even very small spectral differences which cannot be observable with the naked eye. Therefore, the data were analyzed both by OPLS-DA and SIMCA and the second derivative of whole mid-infrared spectra (4000-650 $\mathrm{cm}^{-1}$ ) with 3351 variables was used in the analysis to eliminate noises in the spectra and shifts in the baseline. The number of PC required to construct the model is $(2+2)$. An OPLS-DA model constructed with mid-IR data has a $\mathrm{R}^{2}$ (calibration) of 0.22 and $\mathrm{R}^{2}$ (cross-validation) of 0.26 . The First PC of the model explains $14 \%$ of the variability and the variability corresponding to 
6• O. Uncu, B. Ozen and F. Tokatli

TABLE 2. Misclassification table for OPLS-DA models constructed with fatty acid profile and mid-IR spectral data.

\begin{tabular}{|c|c|c|c|c|c|c|c|c|}
\hline & Members & Correct & Pure SU & Pure SA & $10 \%$ & $30 \%$ & $50 \%$ & $60 \%$ \\
\hline \multicolumn{9}{|l|}{ Fatty acid profile } \\
\hline Pure sunflower oil & 9 & $66.7 \%$ & 6 & 0 & 3 & 0 & 0 & 0 \\
\hline Pure safflower oil & 6 & $100 \%$ & 0 & 6 & 0 & 0 & 0 & 0 \\
\hline $10 \%$ & 54 & $44.4 \%$ & 30 & 0 & 24 & 0 & 0 & 0 \\
\hline $30 \%$ & 54 & $75.9 \%$ & 13 & 0 & 0 & 41 & 0 & 0 \\
\hline $50 \%$ & 54 & $88.9 \%$ & 0 & 0 & 0 & 1 & 48 & 5 \\
\hline $60 \%$ & 50 & $74 \%$ & 0 & 0 & 0 & 0 & 13 & 37 \\
\hline No class & 0 & & 0 & 0 & 0 & 0 & 0 & 0 \\
\hline Total & 227 & $71.4 \%$ & 49 & 6 & 27 & 42 & 61 & 42 \\
\hline \multicolumn{9}{|l|}{ Mid-IR profile } \\
\hline Pure sunflower oil & 9 & $100 \%$ & 9 & 0 & 0 & 0 & 0 & 0 \\
\hline Pure safflower oil & 6 & $100 \%$ & 0 & 6 & 0 & 0 & 0 & 0 \\
\hline $10 \%$ & 54 & $100 \%$ & 0 & 0 & 54 & 0 & 0 & 0 \\
\hline $30 \%$ & 54 & $85.2 \%$ & 0 & 0 & 8 & 46 & 0 & 0 \\
\hline $50 \%$ & 54 & $74.1 \%$ & 0 & 0 & 0 & 2 & 40 & 12 \\
\hline $60 \%$ & 50 & $98 \%$ & 0 & 0 & 0 & 0 & 1 & 49 \\
\hline No class & 0 & & 0 & 0 & 0 & 0 & 0 & 0 \\
\hline Total & 227 & $89.9 \%$ & 9 & 6 & 62 & 48 & 41 & 61 \\
\hline
\end{tabular}

(a)

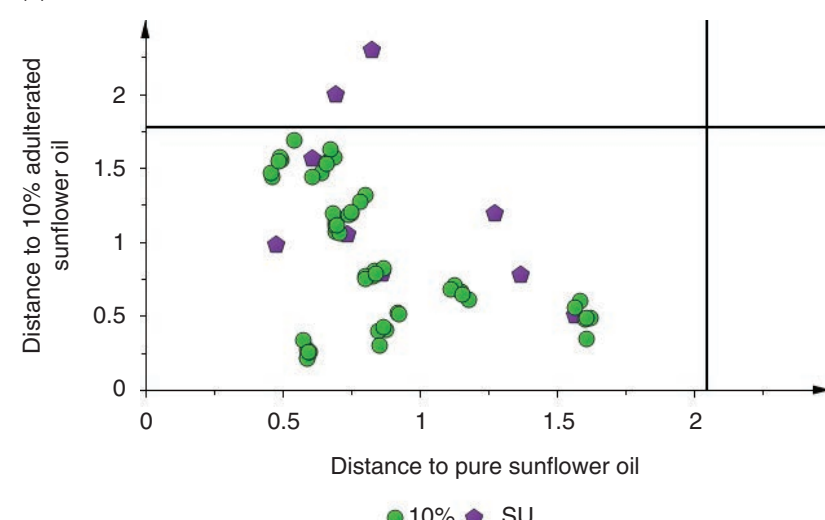

(c)

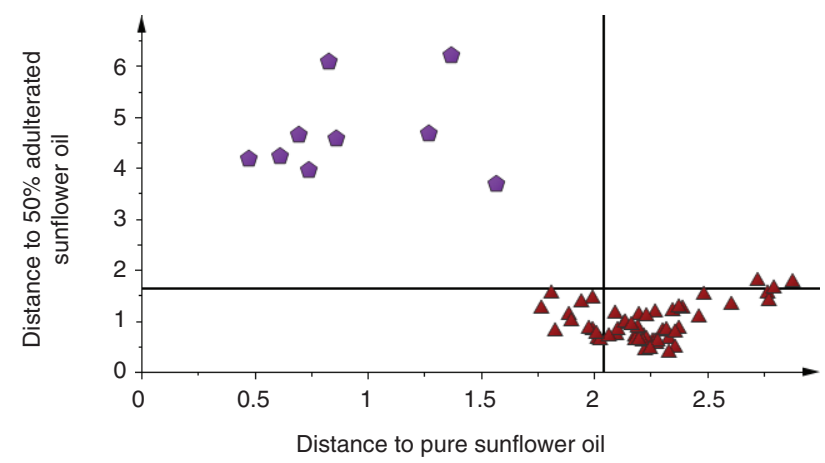

- $50 \%$ SU (b)

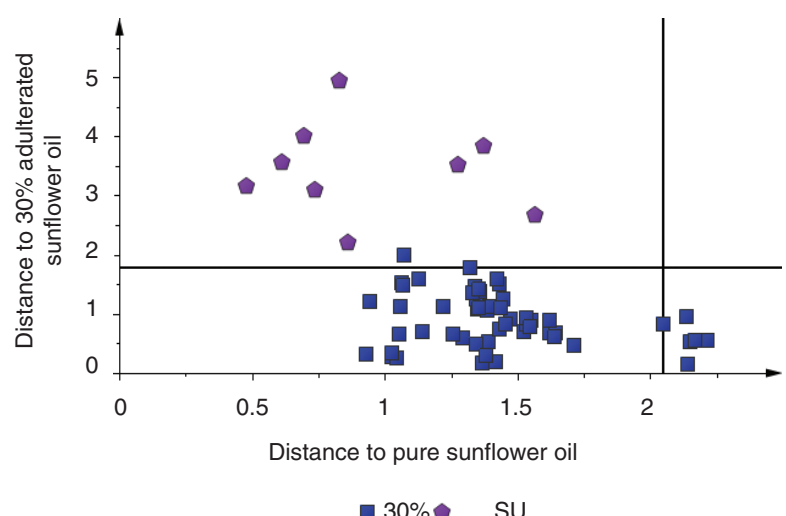

(d)

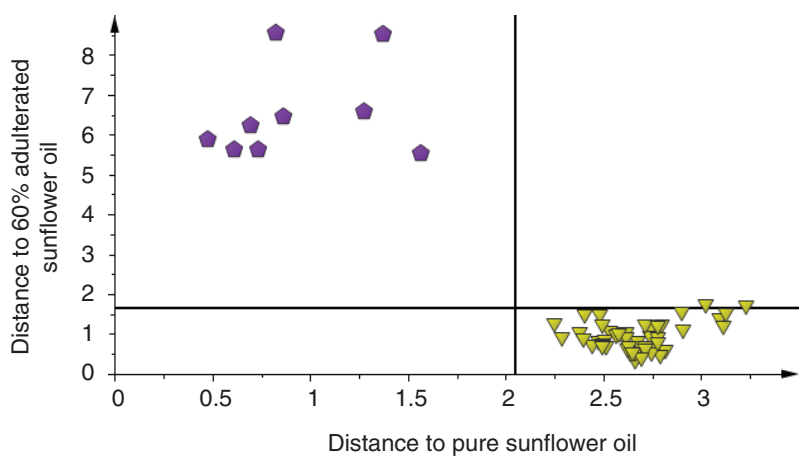

$\nabla 60 \%$ SU

Figure 2. Coomans' plots of fatty acid profiles of (a) $10 \%$, (b) $30 \%$, (c) $50 \%$, and (d) $60 \%$ adulterated sunflower oil (SU) samples with safflower (SA) versus pure sunflower oil samples. 


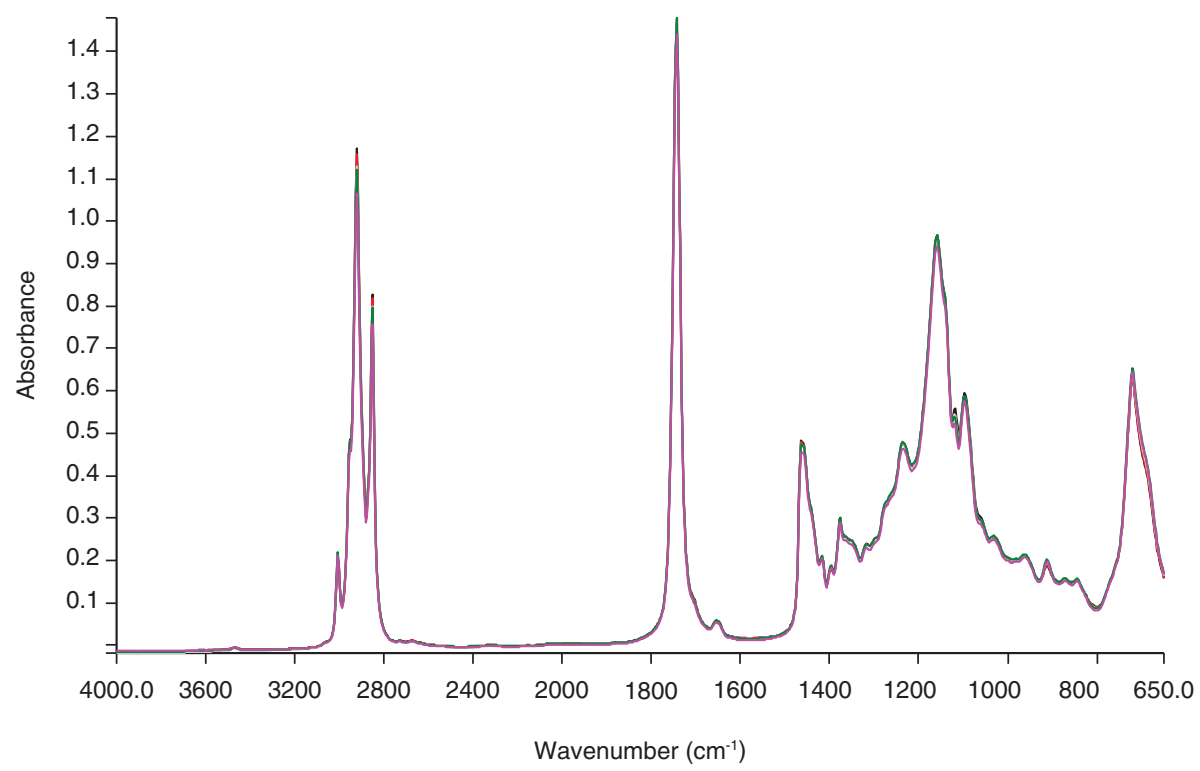

FIGURE 3. Example FTIR spectra of pure sunflower oil and sunflower oil adulterated with safflower oil at $60 \%$ level.

the second $\mathrm{PC}$ is $8 \%$. Low $\mathrm{R}^{2}$ can be explained by the location of pure oil samples outside the control ellipse whereas mixtures are placed inside the ellipse (Figure 4). In addition, the mixtures are separated depending on their percentages although there are overlaps in some cases. The VIP values for the model indicated that wavenumbers responsible for differentiation fit the well-known absorption bands (1815-659, 3146-2816, 3391-3382, 3631-3530 cm $\mathrm{cm}^{-1}$ ) of a general oil spectrum. Peaks around the 3600 $3500 \mathrm{~cm}^{-1}$ region could be attributed to $-\mathrm{OH}$ stretching while the $3300-2800 \mathrm{~cm}^{-1}$ region is associated with $-\mathrm{CH}$ stretching. The $\mathrm{C}-\mathrm{O}$ stretch takes place at $1800-1700 \mathrm{~cm}^{-1}$ and $1200-650 \mathrm{~cm}^{-1}$ is the fingerprint region. Misclassification results for OPLS-DA models constructed using FTIR data are also given in Table 2. This table shows that there is no misclassification even at the $10 \%$ adulteration level. Some of the mixtures were misplaced to inaccurate mixture percentages at higher levels; however, none of these mixtures were classified as pure sunflower oil.

To further investigate the detection limit, mid-IR spectra were also analyzed with SIMCA (Figure 5). The Cooman plot (Figure 5a) obtained from SIMCA showed that the separation between pure sunflower oil and $10 \%$ mixtures was not successful. At the $30 \%$ level only two samples were in the common region but the rest were perfectly separated from the pure sunflower oils (Figure $5 b$ ). Differentiation was also perfect with 50 and $60 \%$ mixtures versus pure oil, according to Figure 5c and 5d, respectively. The detection limit obtained from the OPLS-DA model is lower compared to the SIMCA results as it is the same with the OPLS-DA model developed with the fatty acid profile data.
Mid-IR spectroscopy could detect very low levels of adulteration in the oils. It was reported that palm oil in extra virgin olive oil could be determined at the 1\% level with FTIR spectroscopy (Rohman and Che Man, 2010) while 5\% is the critical level for the adulteration of extra virgin olive oil with cottonseed and rapeseed oils (Gurdeniz and Ozen, 2009). However, the detection limit of adulteration could be higher due to the similar nature of oils that are mixed as in hazelnut oil-olive oil mixtures. The detection limit for these mixtures was reported as 25\% (Ozen and Mauer, 2002). The critical detection limit of $30 \%$ found in this study for safflower oil adulteration of sunflower oil might seem a high value. However, laborious sterol analysis requiring long analysis time is the current method used to detect adulteration for a safflower-sunflower oil mixture. Since there are overlaps in the sterol ranges of these oils (Codex, 2017), detection limits for this analysis might not be very low although there is no study in the literature regarding this issue. In addition, the adulteration percentages encountered for this oil are not very low (oral communication) and the oil industry needs rapid analysis techniques for cases requiring quick decision making. Therefore, a rapid FTIR analysis could still be a valuable tool as a screening method and suspicious samples could be further evaluated with other methods.

Mid-IR spectra were also used in the prediction of adulteration percentages of sunflower oils and PLS regression models of both raw and second derivative spectral data were developed for this purpose. Calibration models were constructed with 150 samples ( $66 \%$ of all samples) and 77 samples were used for the external validation of both 


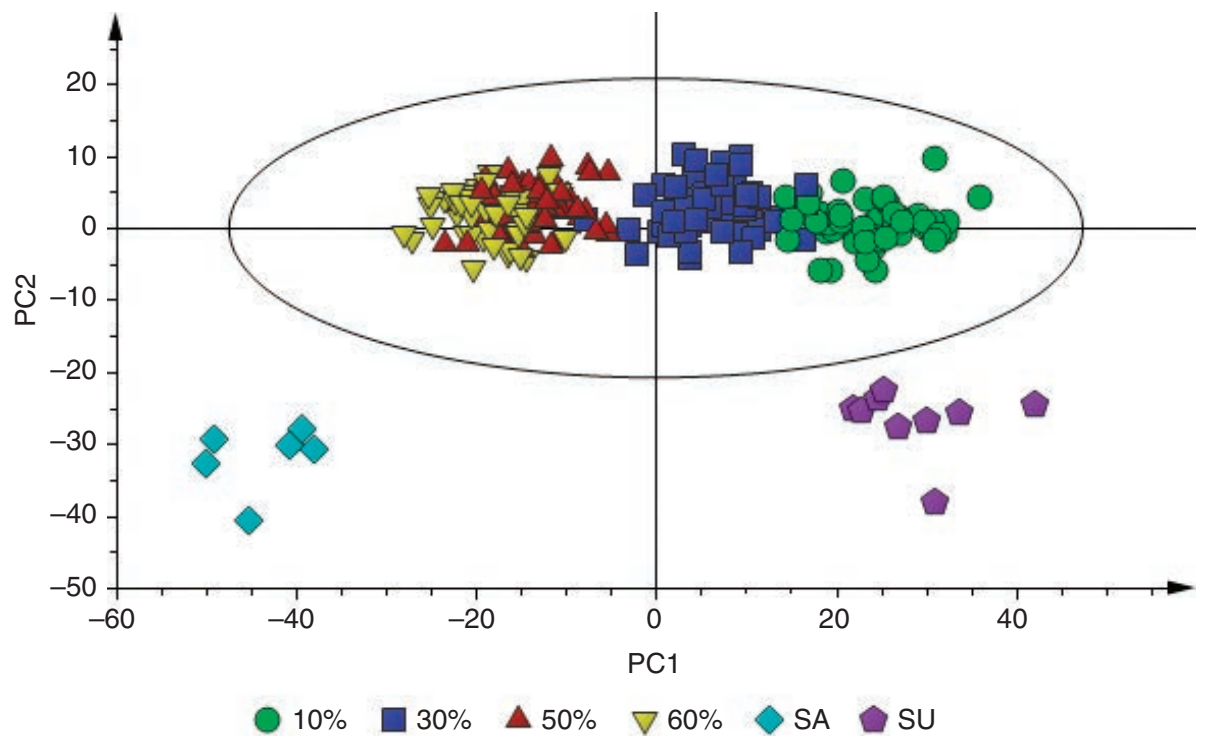

FIGURE 4. Score plot of an OPLS-DA model constructed with FTIR profiles of pure sunflower (SU) and safflower (SA) oil samples and mixtures of safflower oil in sunflower oil at varying levels.
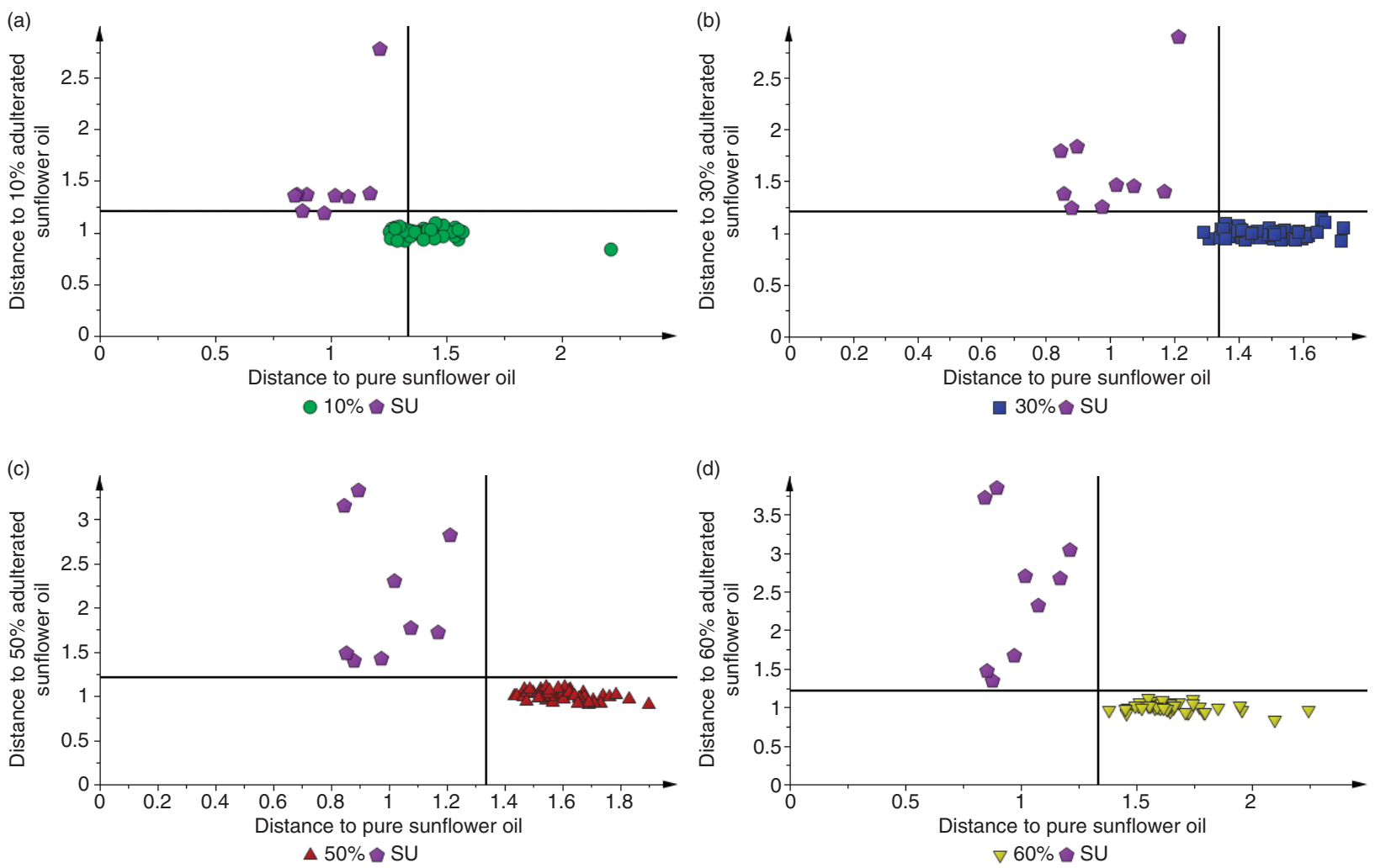

Figure 5. Coomans' plots of FTIR profile of (a) 10\%, (b) 30\%, (c) 50\%, and (d) $60 \%$ adulterated sunflower oil (SU) samples with safflower (SA) versus pure sunflower oil samples.

models. Validation samples were randomly selected from each adulteration level. The statistical parameters of the PLS model developed from the raw data are $\mathrm{R}^{2}$ (calibration) $=0.96, \mathrm{R}^{2}$ (external validation) $=0.93, \mathrm{R}^{2}$ (cross-validation $)=0.9, \mathrm{RMSEE}=4.47$,
RMSEP $=5.68$, RMSEcv $=9.03$. The PLS model of second derivative data resulted in statistical parameters of $\mathrm{R}^{2}$ (calibration) $=0.99, \mathrm{R}^{2}$ (external validation $)=0.83, \mathrm{R}^{2}($ cross-validation $)=0.79$, RMSEE $=2.26$, RMSEP $=8.71$, RMSEcv $=10.56$. 


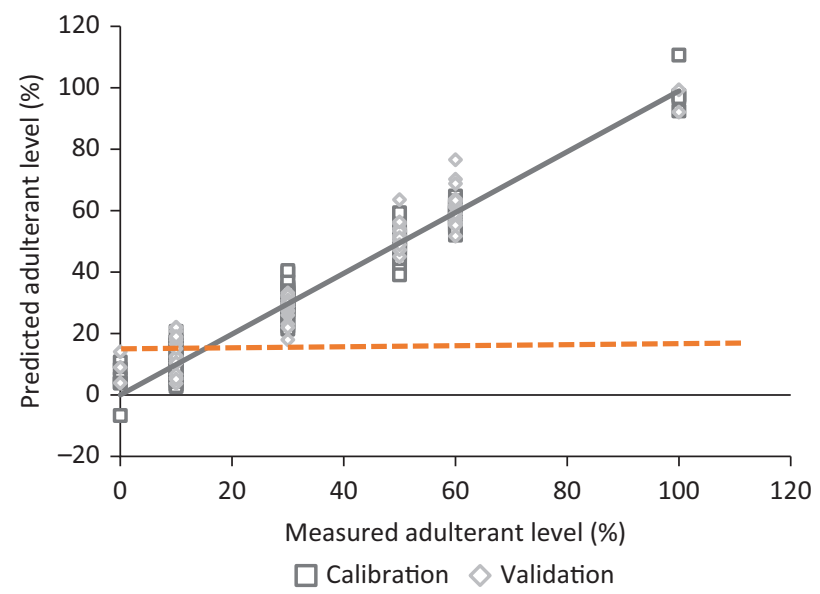

FIGURE 6. Plot of measured versus predicted adulterant levels of sunflower oil generated from PLS regression of raw FTIR spectra.

According to these statistical parameters, raw data were found more efficient than the second derivative in the prediction of adulteration. The $\mathrm{R}^{2}$ and RMSE values for the PLS model built with 10 PC from raw data indicate that the model is very effective in estimating the adulteration level. Figure 6 shows the correlation between actual adulteration percentages and adulteration levels predicted with FTIR spectroscopy. There are overlaps in the prediction of $10 \%$ adulteration level with pure sunflower oil while the estimated values of $30 \%$ mixture do not intersect with pure oil (Figure 6). Therefore, this could be regarded as an indication of $30 \%$ critical limit of adulteration detection level for sunflower oil with safflower oil.

\section{CONCLUSIONS}

To detect the adulteration of sunflower oil with safflower oil, two approaches, fatty acid profile and mid-IR spectroscopy analyses, in combination with various chemometric techniques, were used in this study. Adulteration could be detected at levels as low as 10 and $30 \%$ with the OPLS-DA and SIMCA of mid-IR spectral data, respectively; while a higher level of adulteration of around 50-60\% could be determined with fatty acid analysis data, as confirmed by different chemometric techniques. In other words, FTIR spectroscopy is more promising than fatty acid analysis for the adulteration detection of sunflower oil admixture with safflower oil. This could be explained by the fact that midIR analysis reveals the overall chemical information including fatty acid profile at molecular level which is much more informative than the fatty acid analysis alone. Moreover, very similar fatty acid profiles of sunflower and safflower oils can lead to unsatisfactory differentiation between adulterated sunflower oil and pure sunflower oil samples with fatty acid analysis. Since, FTIR spectroscopy is a rapid technique with minimum waste generation it could be used as a screening tool to check the authenticity of sunflower oil.

\section{ACKNOWLEDGEMENTS}

We would like to thank The Environmental Research Center of Izmir Institute of Technology for their assistance in GC analyses.

\section{REFERENCES}

Aparicio R, Morales MT, Aparicio-Ruiz R, Tena N, GarcíaGonzález DL. 2013. Authenticity of olive oil: Mapping and comparing official methods and promising alternatives. Food Res. Int. 54, 2025-2038. https://doi.org/10.1016/j. foodres.2013.07.039

Azizian H, Mossoba MM, Fardin-Kia AR, Delmonte P, Karunathilaka SR, Kramer JKG. 2015. Novel, rapid identification, and quantification of adulterants in extra virgin olive oil using near-infrared spectroscopy and chemometrics. Lipids 50, 705-718. https://doi.org/10.1007/ s11745-015-4038-4

Christopoulou E, Lazaraki M, Komaitis M, Kaselimis K. 2004. Effectiveness of determinations of fatty acids and triglycerides for the detection of adulteration of olive oils with vegetable oils. Food Chem. 84, 463-474. https://doi. org/10.1016/S0308-8146(03)00273-5

Cosge B, Gurbuz B, Kiralan M. 2007. Oil content and fatty acid composition of some safflower (Carthamus tinctorius L.) varieties sown in spring and winter. Int. J. Nat. Eng. Sci. 1, 11-15.

Codex. 2017. Codex Standard for Named Vegetable Oils. CODEX STAN 210-1999. (assessed May, 2018) http://www.fao.org/ fao-who-codexalimentarius/sh-proxy/it/?lnk=1\&url=https $\% 253 \mathrm{~A} \% 252 \mathrm{~F} \% 252 \mathrm{~F}$ workspace.fao.org $\% 252 \mathrm{Fsites} \% 252 \mathrm{Fc}$ odex $\% 252$ FStandards $\% 252$ FCODEX $\% 2$ BSTAN $\% 2 B 210$ 1999\%252FCXS 210e.pdf

Ellis DI, Brewster VL, Dunn WB, Allwood JW, Golovanov AP, Goodacre R. 2012. Fingerprinting food: current technologies for the detection of food adulteration and contamination. Chem. Soc. Rev. 41, 5706-5727. https://doi.org/10.1039/ C2CS35138B

European Union Commission. 1991. European Union Commission Regulation EEC 2568/91 on the characteristics of olive oil and olive-residue oil and on the relevant methods of analysis. Off J Eur Comm. L248 (1991).

Hurriyet 2016. (assessed May, 2018) Aycicegi yaglari ile ilgili cok carpici uyari. http://www.hurriyet.com.tr/eko-bitkiselyag-sanayicilerinden-tagsis-40140305

Fernández-Martínez J, Rio MD, Haro AD. 1993. Survey of safflower (Carthamus tinctorius L.) germplasm for variants in fatty acid composition and other seed characters. Euphytica 69, 115-122.

Gecgel U, Demirci M, Esendal E, Tasan M. 2007. Fatty acid composition of the oil from developing seeds of different varieties of safflower (Carthamus tinctorius L.). J. Am. Oil Chem. Soc. 84, 47-54. https://doi.org/10.1007/s11746-006-1007-3

Gómez-Caravaca AM, Maggio RM, Cerretani L. 2016. Chemometric applications to assess quality and critical parameters of virgin and extra-virgin olive oil. A review. Anal Chim. Acta 913, 1-21. https://doi.org/10.1016/j.aca. 2016.01.025

Guillén MD, Cabo N. 1997. Infrared spectroscopy in the study of edible oils and fats. $J$. Sci. Food Agric. 75, 1-11. https:// doi.org/10.1002/(SICI)1097-0010(199709)75:1<1::AIDJSFA842>3.0.CO;2-R

Gurdeniz G, Ozen B. 2009. Detection of adulteration of extravirgin olive oil by chemometric analysis of mid-infrared spectral data. Food Chem. 116, 519-525. https://doi.org/ 10.1016/j.foodchem.2009.02.068 
Jabeur H, Zribi A, Makni J, Rebai A, Abdelhedi R, Bouaziz M. 2014. Detection of Chemlali extra-virgin olive oil adulteration mixed with soybean oil, corn oil, and sunflower oil by using GC and HPLC. J. Agric. Food Chem. 62, 4893-4904. https://doi.org/10.1021/jf500571n

Jha SN, Jaiswal P, Grewal MK, Gupta M, Bhardwaj R. 2016. Detection of adulterants and contaminants in liquid foodsa review. Crit. Rev. Food Sci. Nutr. 56, 1662-1684. https:// doi.org/10.1080/10408398.2013.798257

Karoui R, Fernández Pierna JA, Dufour E. 2008. Spectroscopic technique: Mid- infrared (MIR) and Fourier transform mid-infrared (FT-MIR) spectroscopies, in Sun DW (Ed.). Modern Techniques for Food Authentication. Academic Press, Oxford, UK, pp. 27-64

Knowles PF. 1989. Safflower, in Downey RK, Röbbelen G, Ashri A. (Eds.) Oil Crops of the World. McGraw-Hill Inc., New York, pp. 363-374.

Lai YW, Kemsley EK, Wilson RH. 1994. Potential of Fourier transform infrared spectroscopy for the authentication of vegetable oils. J. Agric. Food Chem. 42, 1154-1159. https:// doi.org/10.1021/jf00041a020

Lerma-García MJ, Ramis-Ramos G, Herrero-Martínez JM, Simó-Alfonso EF. 2010. Authentication of extra virgin olive oils by Fourier-transform infrared spectroscopy. Food Chem. 118, 78-83. https://doi.org/10.1016/j.foodchem.2009.04.092

Mendes TO, Rocha RA da, Porto BLS, Oliveira MAL de, Anjos VDC dos, Bell MJV. 2015. Quantification of extra-virgin olive oil adulteration with soybean oil: A comparative study of NIR, MIR, and Raman spectroscopy associated with chemometric approaches. Food Anal. Meth. 8, 2339-2346. https://doi.org/10.1007/s12161-015-0121-y
Ozen BF, Mauer LJ. 2002. Detection of hazelnut oil adulteration using FT-IR spectroscopy. J. Agric. Food Chem. 50, 3898-3901. https://doi.org/10.1021/jf0201834

Rohman A, Che Man YB. 2009. Analysis of cod-liver oil adulteration using Fourier transform infrared (FTIR) spectroscopy. J. Am. Oil Chem. Soc. 86, 1149-1153. https://doi. org/10.1007/s11746-009-1453-9

Rohman A, Che Man YB. 2010. Fourier transform infrared (FTIR) spectroscopy for analysis of extra virgin olive oil adulterated with palm oil. Food Res. Int. 43, 886-892. https://doi.org/10.1016/j.foodres.2009.12.006

Tena N, Wang SC, Aparicio-Ruiz R, García-González DL, Aparicio R. 2015. In-depth assessment of analytical methods for olive oil purity, safety, and quality characterization. J. Agric. Food Chem. 63, 4509-4526. https://doi.org/10.1021/ jf5062265

Velasco L, Fernández-Martínez JM. 2001. Breeding for oil quality in safflower, in Bergman, J. W., Henning Mundel, H. (Eds.) Proceedings of the Vth International Safflower Conference. North Dakota State University: Williston, North Dakota and Sidney, Montana, USA, pp. 133-137.

Wang L, Lee FSC, Wang X, He Y. 2006. Feasibility study of quantifying and discriminating soybean oil adulteration in camellia oils by attenuated total reflectance MIR and fiber optic diffuse reflectance NIR. Food Chem. 95, 529-536. https://doi.org/10.1016/j.foodchem.2005.04.015

Yeilaghi H, Arzani A. Ghaderian M, Fotovat R, Feizi M, Pourdad SS. 2012. Effect of salinity on seed oil content and fatty acid composition of safflower (Carthamus tinctorius L.) genotypes. Food Chem. 130, 618-625. https://doi. org/10.1016/j.foodchem.2011.07.085 